\title{
Foreword of the 4th International Symposium on Nuclear Analytical Chemistry (NAC-IV)
}

\author{
A. V. R. Reddy $\cdot$ R. Acharya
}

Received: 25 July 2012/Published online: 25 August 2012

(C) Akadémiai Kiadó, Budapest, Hungary 2012

The Fourth International Symposium on Nuclear Analytical Chemistry (NAC-IV) was organized at the Bhabha Atomic Research Centre (BARC), Department of Atomic Energy, Mumbai, India during November 15-19, 2010. NAC-IV was held in India for the first time. Previous three NAC symposia (NAC I-III) were held in Canada; Halifax (1985), Toronto (1992) and Halifax (2001). These symposia are organized periodically to provide a forum to exchange information on recent developments and applications of nuclear analytical chemistry. The NAC-IV symposium was sponsored by the Board of Research in Nuclear Sciences (BRNS), Department of Atomic Energy (DAE), India, and co-organized by the Indian Association of Nuclear Chemists and Allied Scientists (IANCAS). About 300 delegates from various units of DAE \& Academic Institutes in India and 27 overseas delegates from 13 different countries participated in NAC-IV.

Dr. Srikumar Banerjee, then Chairman of the Atomic Energy Commission (AEC) and Secretary, DAE, Government of India, inaugurated NAC-IV and Dr. R. K. Sinha, Chairman, AEC (then Direcor, BARC) presided over the inaugural session. Dr. Banerjee in his keynote address spoke about some interesting applications of analytical techniques in general and the role of nuclear analytical

\footnotetext{
A. V. R. Reddy

Analytical Chemistry Division, BARC, Trombay,

Mumbai 400 085, India

e-mail: avreddy@barc.gov.in

R. Acharya $(\square)$

Radiochemistry Division, BARC, Trombay,

Mumbai 400 085, India

e-mail: racharya@barc.gov.in
}

techniques (NATs) in particular in both R\&D and nuclear reactor technology. Dr. Sinha emphasized the role of different NATs including neutron activation analysis (NAA) and prompt gamma ray NAA (PGNAA) in various programs of BARC and DAE, and also gave a brief account of the nuclear analytical facilities at BARC. Dr. Banerjee released the Book of Abstracts of NAC-IV and Dr. Sinha released the IANCAS Special Bulletin.

Dr. A. V. R. Reddy, Head, Analytical Chemistry Division, BARC, and Convener, organizing Committee and Co-Chairman of the NAC-IV Technical Committee welcomed the delegates and outlined the theme of NAC-IV. Dr. V. Venugopal, Chairman of NAC-IV and then Director, Radiochemistry and Isotopes (RC\&I) Group, BARC, emphasized that NATs using reactor and accelerator facilities were very important to obtain results with high precision and accuracy. Prof. A. Chatt of Dalhousie University, Canada, President of the NAC symposia series as well as the Co-Chairman of the NAC-IV Technical Committee, gave a brief account of the main objectives of these symposia. He informed that the Journal of Radioanalytical and Nuclear Chemistry (JRNC), has agreed to publish the peer-reviewed full papers of NAC-IV in two issues of JRNC. Dr. R. Acharya, RCD, BARC and Secretary of NAC-IV proposed a vote of thanks.

The scope of NAC-IV included conventional and prompt gamma-ray activation analysis, alpha, X-ray \& gamma-ray spectrometry, nuclear analytical chemistry in nuclear fuel cycle, nuclear track techniques, nuclear probes and ion beam analysis techniques, radioisotope tracer methodologies, speciation studies, QA/QC in measurements, applications of NATs to archaeological, biological, environmental, geological, industrial, nutritional, nuclear and pharmaceutical materials, nuclear forensics and safety studies. The technical program consisted of 30 invited talks 
Fig. 1 Inauguration of NAC-IV and release of book of abstracts

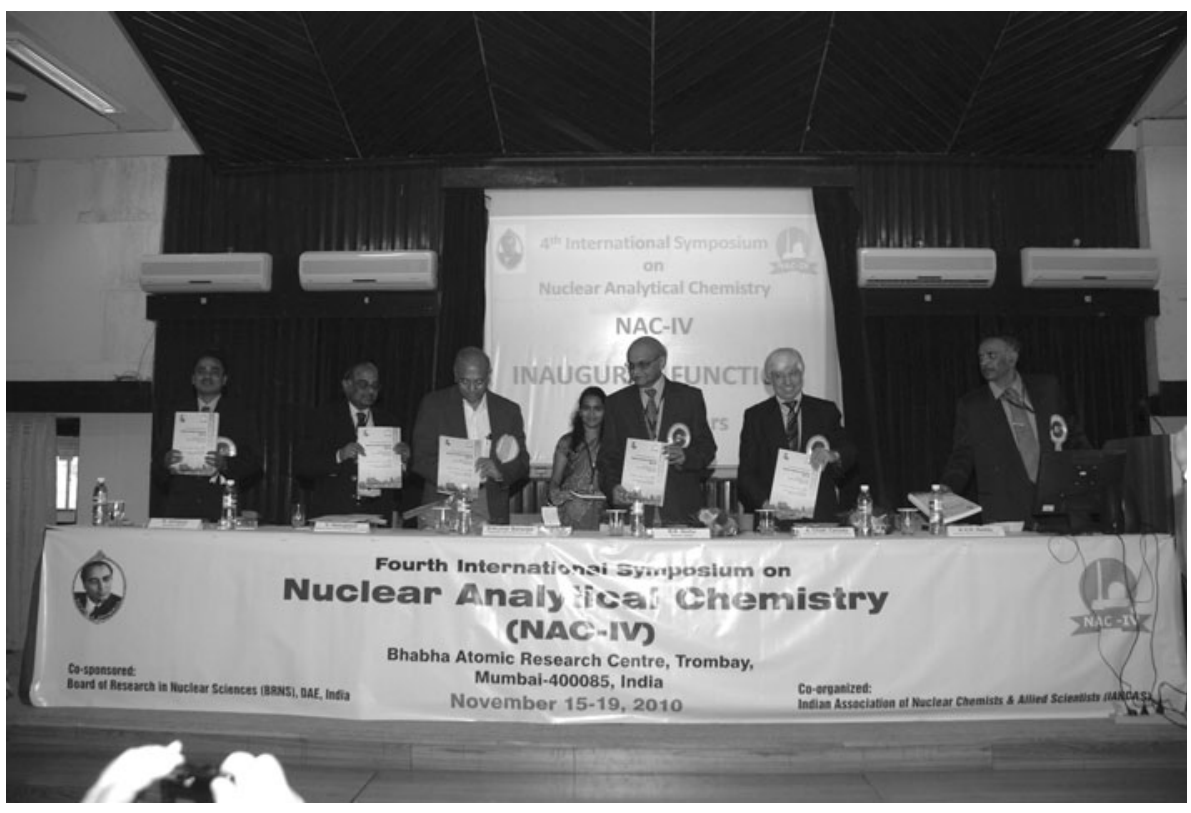

Fig. 2 Inauguration of NAC-IV and release of IANCAS special bulletin

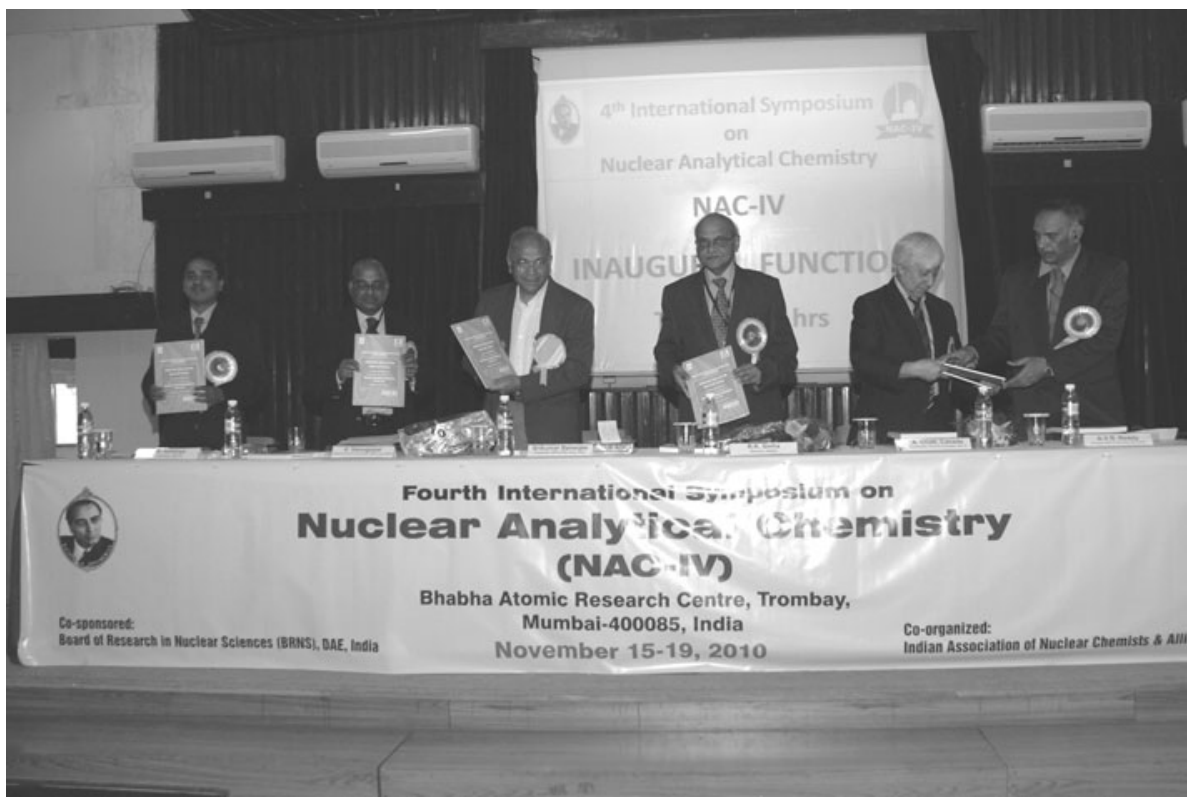

by experts from India and abroad as well as 215 contributed papers (oral and poster) selected after a thorough review by two experts. Technical committee gave preference to young researchers and $\mathrm{PhD}$ scholars for oral presentations. A special poster session was held on the facilities for NATs that are used for R\&D studies in various countries.

On the last day of the symposium a panel discussion preceded the valedictory function. The panel was chaired by Dr. D. D. Sood, former Director, RC\&I Group, BARC, and former Director of Physical and Chemical Division,
IAEA. The other panel members, Prof. Z. R. Turel (India), Dr. A. V. R. Reddy (BARC), Dr. T. Mukherjee (BARC), Prof. A. Chatt (Canada), Dr. R. R. Greenberg (USA), Prof. H. Nitsche (USA) and Prof. M. Ebihara (Japan) gave valuable remarks on various aspects of NATs. Dr. P. Vermaercke (Belgium) and Dr. Sirinart L (Thailand) spoke on the technical contents of NAC-IV. The panel members were pleased for the effective use of NATs in various fields. It was felt that there is a need for continuing with sustained efforts to achieve high standards and quality results, and panel members urged the participants to strive 
Fig. 3 Delegates of

NAC-IV (1)
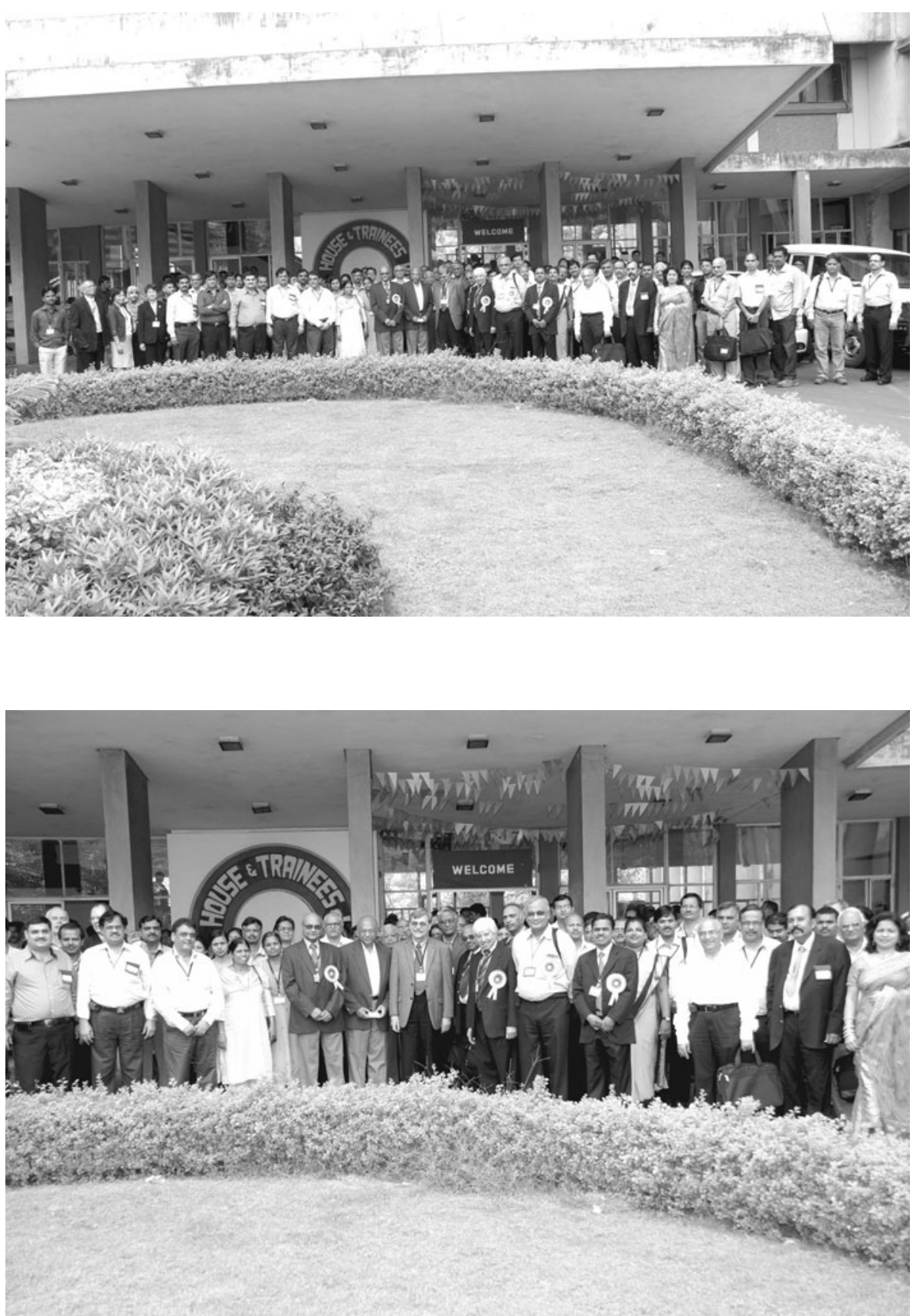

Fig. 4 Delegates of NAC-IV (2) hard in this direction. The valedictory function was chaired by Dr. V. Venugopal and attended by many members of the NAC-IV International Committee, Local Organizing Committee, and Technical Committee. Dr. V. Venugopal announced that next NAC (NAC-V) will be organized at BARC, Mumbai.

Participants enthusiastically gave their feedback. All participants, particularly research students, were benefited by participating in this international symposium in India as they could get an opportunity to interact with peers and experts from India and overseas, and learn the latest developments in NAC vis-a-vis NATs. IANCAS instituted 12 awards for best poster (8) and oral (4) presentations to young scientists and research students. A five member experts committee evaluated all oral and poster presentations and decided the winners. The winners include Dr. M. Maiti, Ms. Sarayu Kasar, Mr. Sumit Jaiswal, Ms. Chhavi Agarwal, Ms. Satyapriya Sreejith, Ms. Nisha Barot, Ms. Sanhita Chaudhury, Mr. Sumit Kumar, Mr. Vimalnath Nair and Dr. K. K. Swain. Dr. V. Venugopal, 
Fig. 5 NAC-IV secretariat scientific team
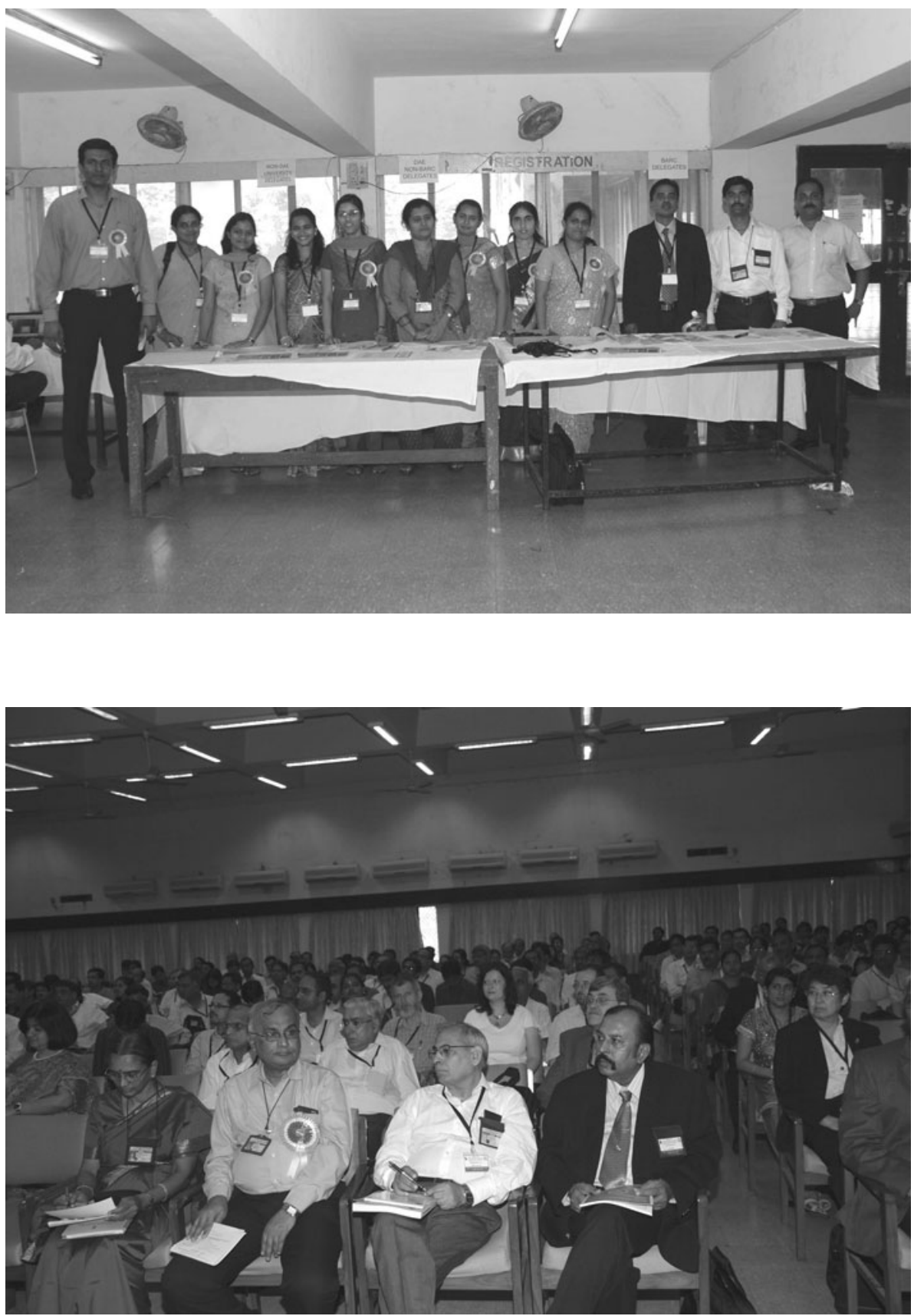

Fig. 6 Delegates of NAC-IV during technical presentation in conference room president, IANCAS distributed the award certificates and cash prizes.

Our thanks are due to a large number of members from BARC, Mumbai, who contributed for the success of NAC-IV and it is difficult to include all the names. We thank all the members of local organizing committee headed by Dr. P. K. Pujari, Head, Nuclear Chemistry Section, RCD, BARC for their untiring efforts during NAC-IV. We would like to place on record our special thanks to Dr. K. K. Swain and Mr. K. Venkatesh,
Analytical Chemistry Division, BARC who have contributed immensely in many ways for the successful organization of NAC-IV. Our special thanks are also due to Dr. R. Verma, Dr. R. K. Singhal, Mr. Amol D. Shinde and Mr. Vishal Koli (ACD, BARC), Dr. P. N. Pathak, Mr. T. P. Chaturvedi, Mr. K. B. Dasari, Mr. Rakesh N. Shinde and Mr. Sumit Chillar (RCD, BARC), Mr. S. Jeyakumar, Mr. M. K. Saxena, Mr. D. B. Paranjape and Mrs. N. Kadam (RACD, BARC), Dr. D. Alamelu (FCD, BARC), Mr. K. Vimalnath Nair, Mr. K. C. Jagadeesan and Mr. S. K. 
Fig. 7 NAC-IV IANCAS best paper award presentation by Dr. V. Venugopal, Chairman, NAC-IV

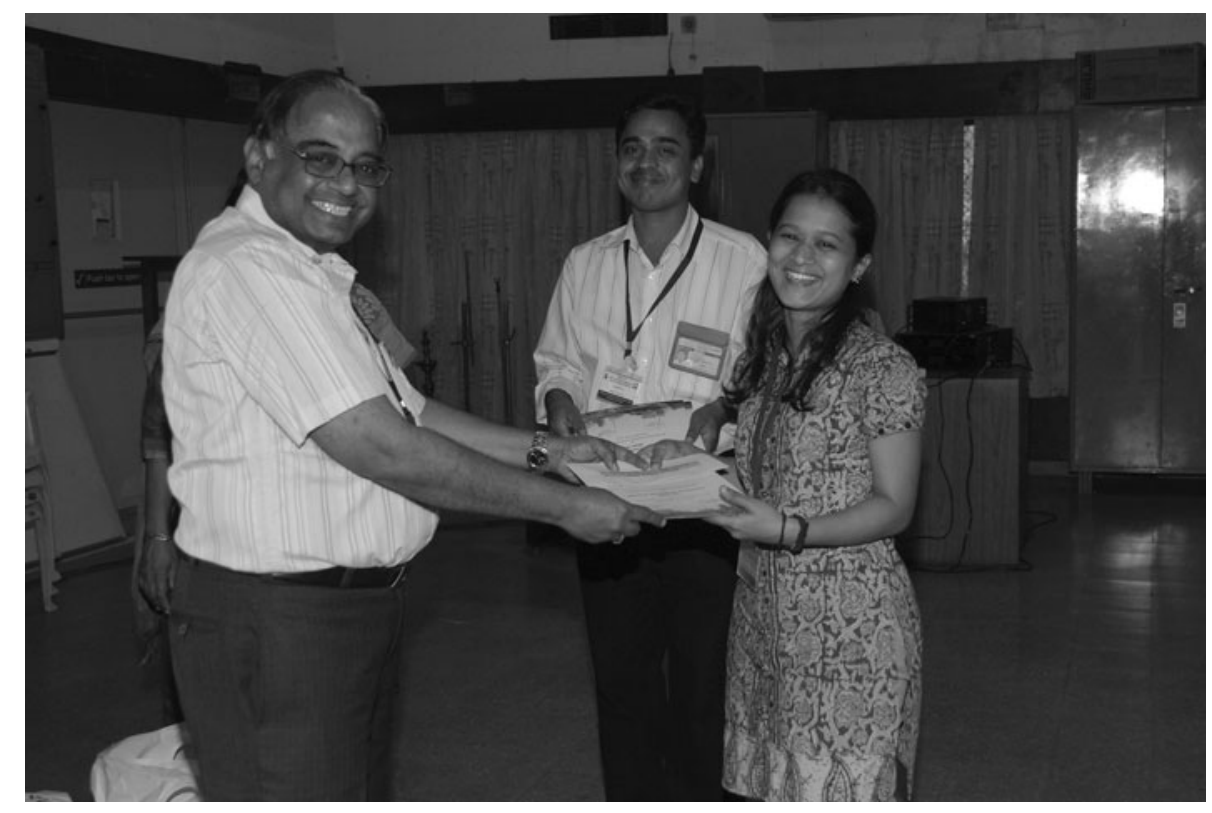

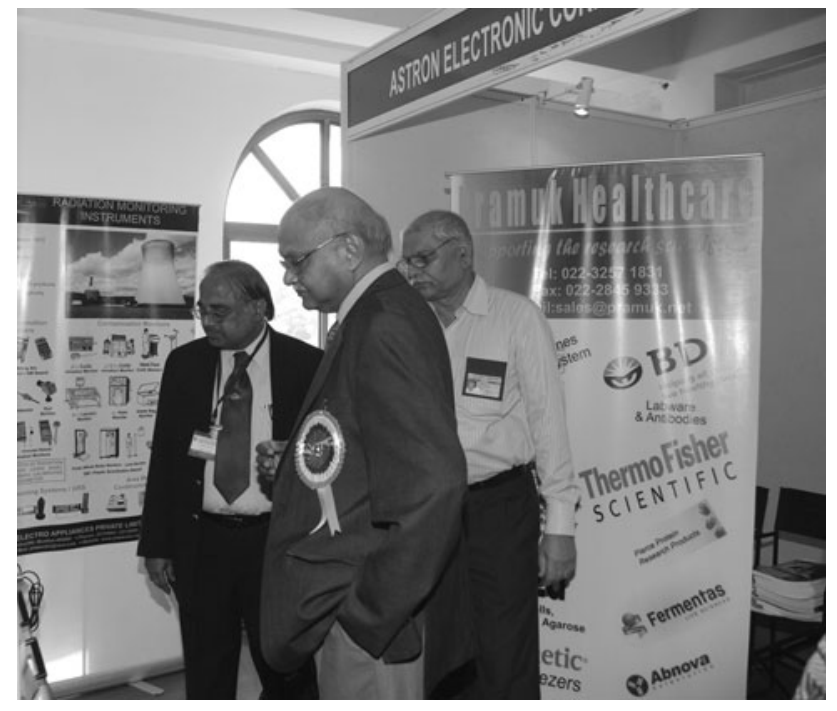

Fig. 8 Dr. R. K. Sinha, Chairman, AEC (then Director, BARC) and Dr. V. Venugopal visiting scientific exhibition during NAC-IV
Saxena (RPhD, BARC), Mr. A. S. Pente (WMD, BARC), Dr. Ziley Singh (PDD, BARC) and Mr. Sharad Nalawade (PD, BARC).

Success of any conference depends on its technical content and we record our appreciation to all the authors/ contributors who have contributed papers to NAC-IV. We are greatful to all the members of technical committee, publication committee and other experts who have critically evaluated the manuscripts for their suitability to include in these issues. It is very satisfying that a total of 85 manuscripts are being published in the special issue and these papers have been critically reviewed by two/ three experts. Our special thanks are due to Prof. T. Braun, Chief Editor, JRNC, Dr. A. Schubert, Editor, JRNC and Prof. A. Chatt, Editor, JRNC and Chief Editor, Special Volumes (Conferences), JRNC for bringing out these NAC-IV JRNC special issues. Figs. 1-10 give glimpses of NAC-IV from Inauguration to Valedictory function respectively. 
Fig. 9 Panel discussion

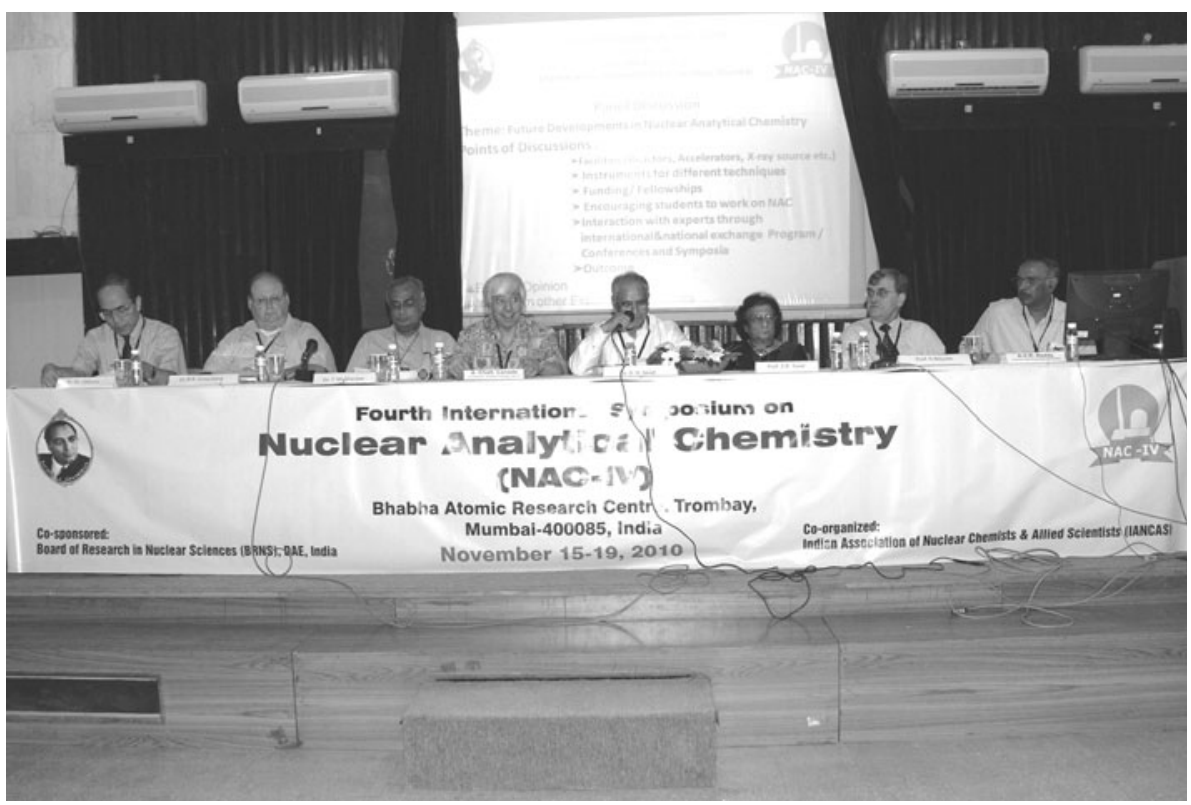

Fig. 10 Valedictory function

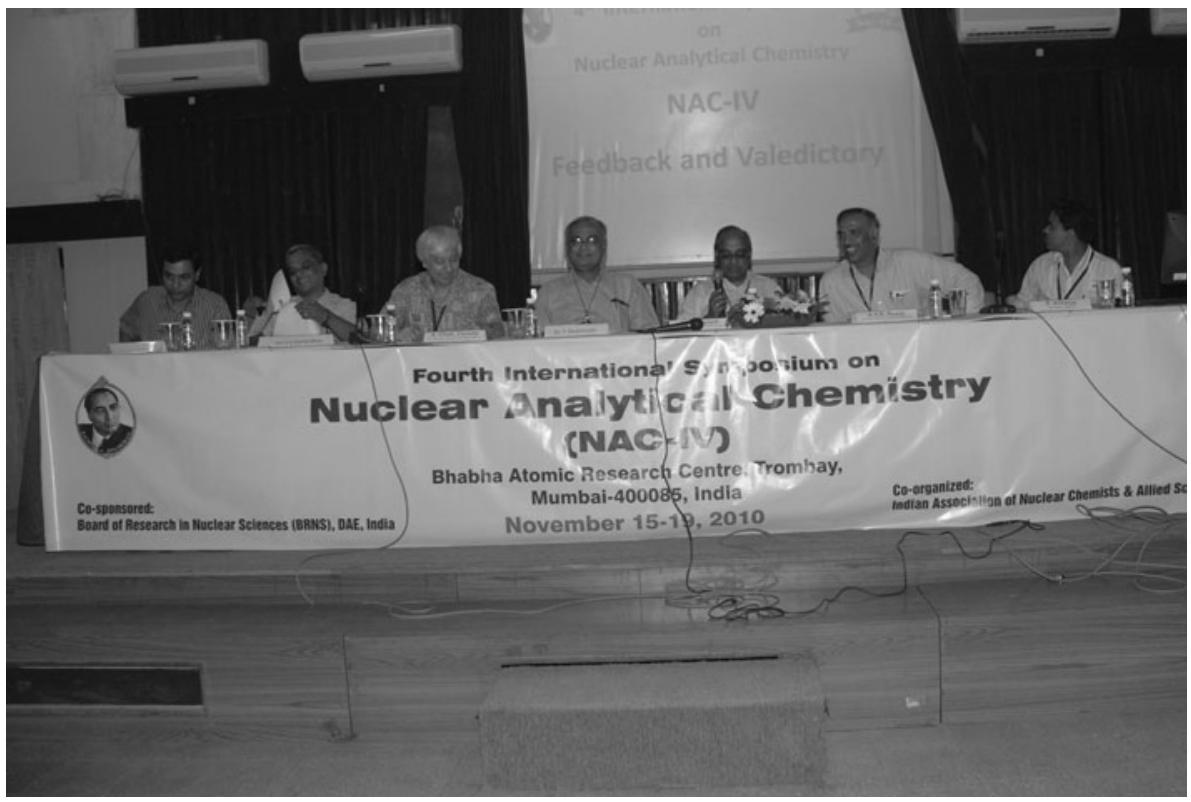

R. Acharya

Secretary

A. V. R. Reddy

Convener

V. Venugopal

Chairman 